\title{
Isolation, Characterization, and Theoretical Study of $\mathrm{La}_{2} @ \mathbf{C}_{78}$
}

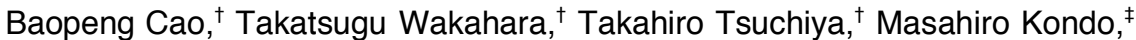 \\ Yutaka Maeda, ${ }^{\dagger}$ G. M. Aminur Rahman, ${ }^{\dagger}$ Takeshi Akasaka, $^{,,}$Kaoru \\ Kobayashi, ${ }^{\$}$ Shigeru Nagase, ${ }^{* \$}$ and Kazunori Yamamoto ${ }^{\#}$ \\ Center for Tsukuba Advanced Research Alliance, University of Tsukuba, Tsukuba, Ibaraki 305- \\ 8577, Japan \\ Institute for Molecular Science, Myodaiji, Okazaki 444-8585, Japan \\ Japan Nuclear Fuel Cycle Development Institute, Tokai, Ibaraki 319-1100, Japan
}

Figure S1. Experimental and simulated theoretical mass spectra (LD TOF MS, negative mode) of isolated $\mathrm{La}_{2} @ \mathrm{C}_{78}$. The experimental and theoretical isotopic distributions (cf. insets in Figure S1) of $\mathrm{La}_{2} @ \mathrm{C}_{78}$ are consistent with each other, indicating the isolation of this species is complete.

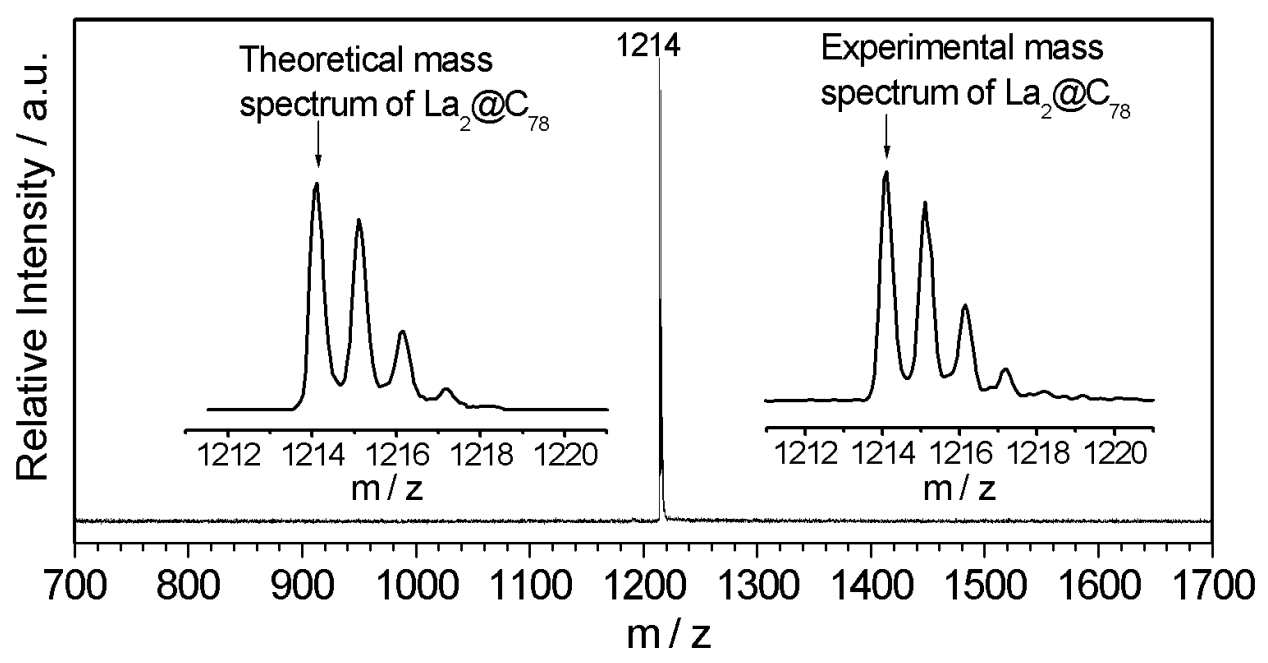

Figure S2. DPV curve of $\mathrm{La}_{2} @ \mathrm{C}_{78}$.

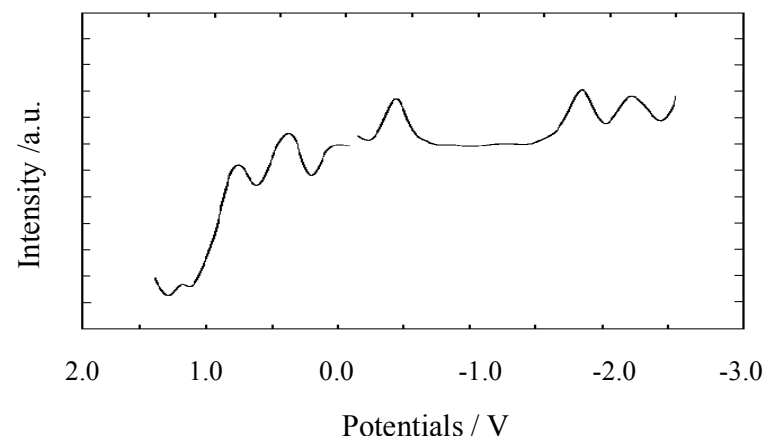

$0.1 \mathrm{M}\left({ }^{\mathrm{n}} \mathrm{Bu}\right)_{4} \mathrm{NPF}_{6}, o$-DCB solution, working electrode Pt wire, BAS - $100 \mathrm{~B} / \mathrm{W}$, potentials vs. ferrocene/ferrocenium couple. 
Figure S3. CV curve (reduction) of $\mathrm{La}_{2} @ \mathrm{C}_{78}$.



$0.1 \mathrm{M}\left({ }^{\mathrm{n}} \mathrm{Bu}\right)_{4} \mathrm{NPF}_{6}, o-\mathrm{DCB}$ solution, working electrode Pt wire, BAS - $100 \mathrm{~B} / \mathrm{W}$, potentials vs. ferrocene/ferrocenium couple. This shows the three reduction processes of $\mathrm{La}_{2} @ \mathrm{C}_{78}$ are reversible.

Figure S4. Mass spectra of reaction mixture of $\mathrm{La}_{2} @ \mathrm{C}_{78}$ with 1,1,2,2-tetrakis(2,4,6trimethylphenyl)-1,2-disirane. (Jeol IMM-SX-102, FAB-MS). a). Photochemical reaction; b). Thermal reaction). Inset is the expended MS of monoadduct. Mono- and bis-adducts are formed from the reaction.
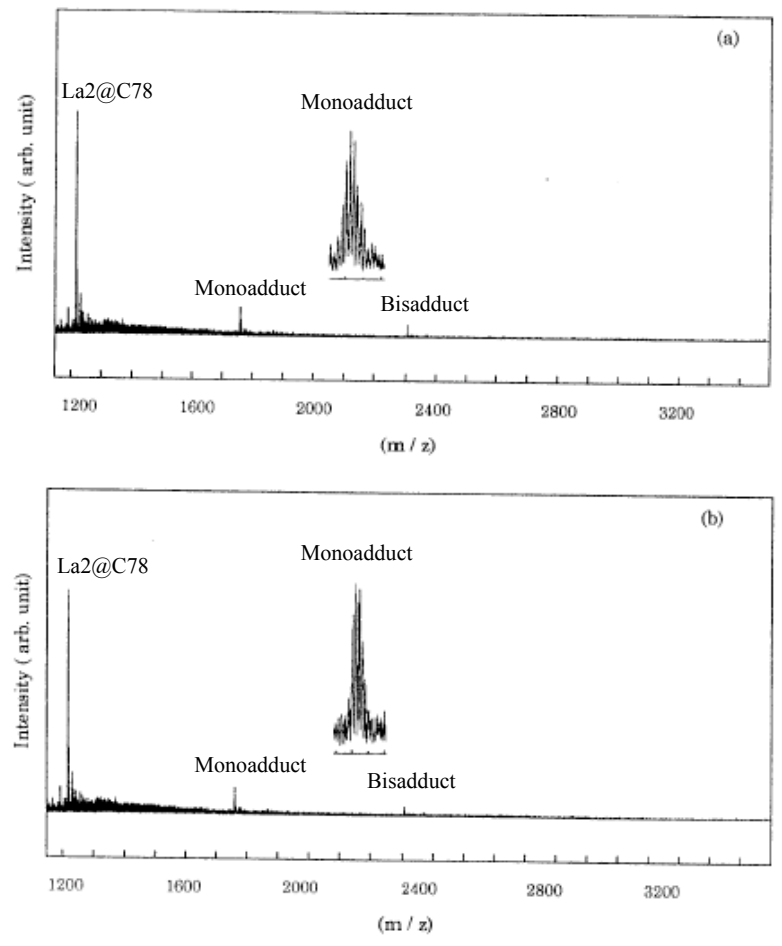
Figure S5. REM orbital maps of the optimized structure of $\mathrm{La}_{2} @ \mathrm{C}_{78}$ : No. 241 to 245 are the occupied orbits; No. 246 to 250 are the unoccupied orbits. No. 245 is the HOMO and No. 246 is the LUMO. Six electrons are transferred from two La-atoms to the cage.

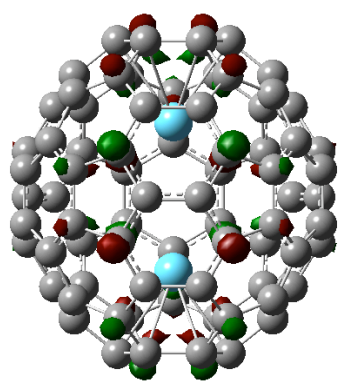

241

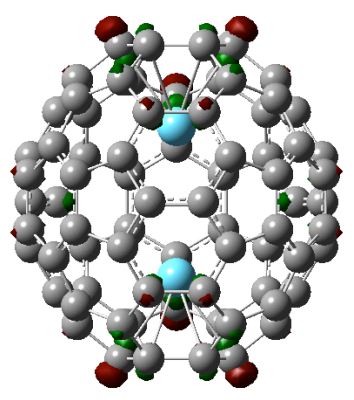

243

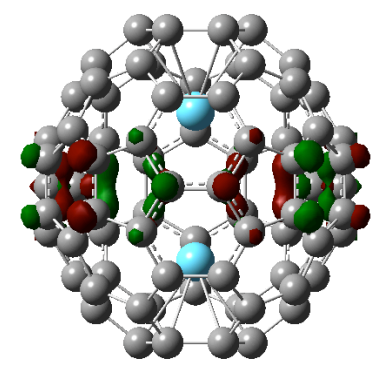

$245 \square \mathrm{HOMO}$

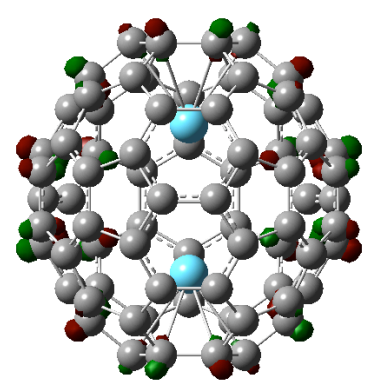

242

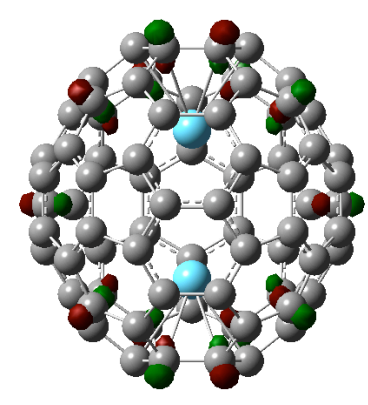

244



$246 \square$ LUMO 


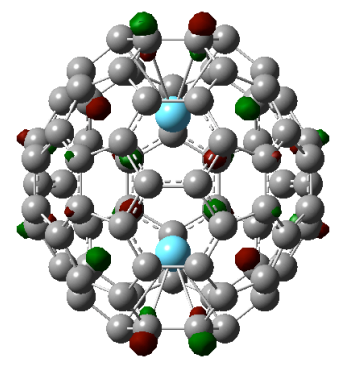

247

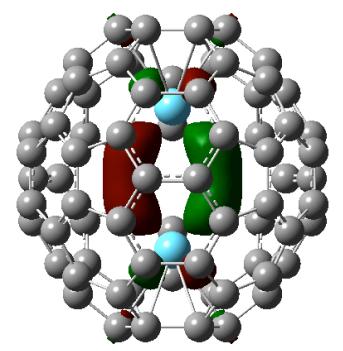

249

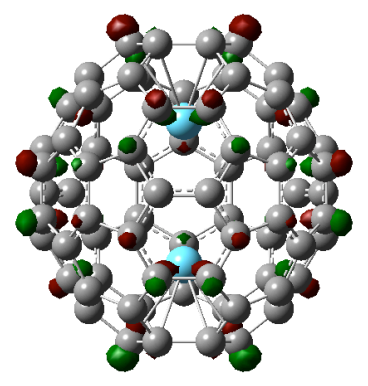

248

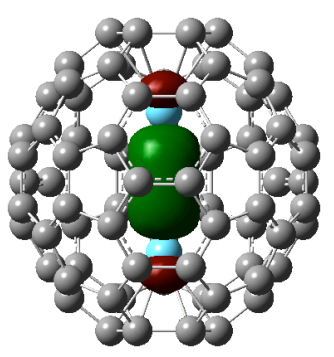

250

Figure S6 Orbital levels of $\mathrm{La}_{2} @ \mathrm{C}_{78}$
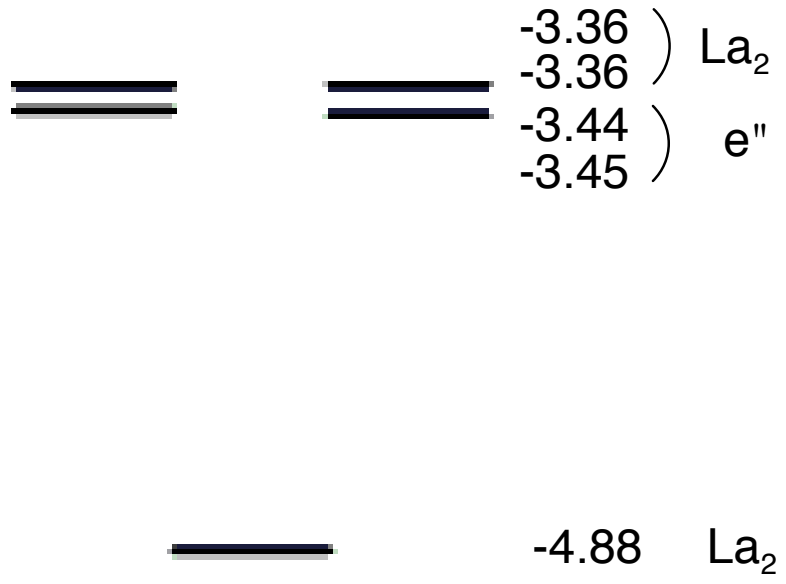

$\left.41+1 \mid \begin{array}{ll}-5.69 & \mathrm{a}_{2}^{\prime} \\ -5.74 \\ -5.75\end{array}\right) \mathrm{e}^{\prime}$

$\left.\frac{1}{1} \quad \frac{1}{1} \quad \begin{array}{c}-6.43 \\ -6.43\end{array}\right) \mathrm{e}^{\prime \prime}$ 
Figure S7. Three structures with two La-atoms located on $\mathrm{x}$ - and $\mathrm{y}$-axes in the $\mathrm{xy}$ mirror plane ( $\square_{h}$ mirror plane, the paper) and on z-axis $\left(C_{3}\right.$ axis, perpendicular to the paper).

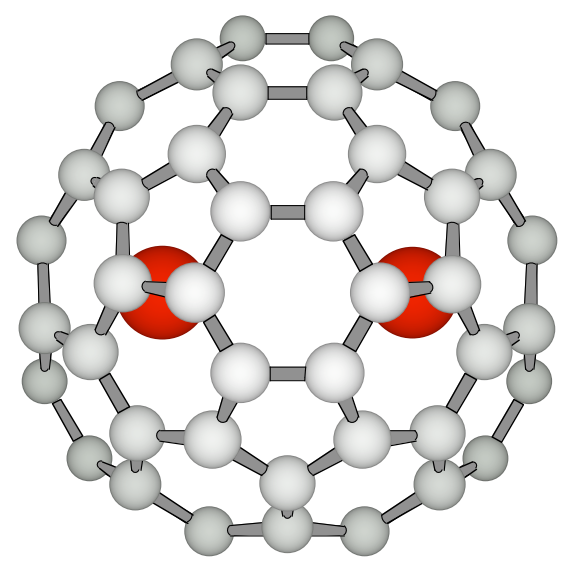

Two La-atoms are located on the $\mathrm{x}$-axis. This structure is less stable by $34 \mathrm{kcal}$ $\mathrm{mol}^{-1}$ than the optimized structure.

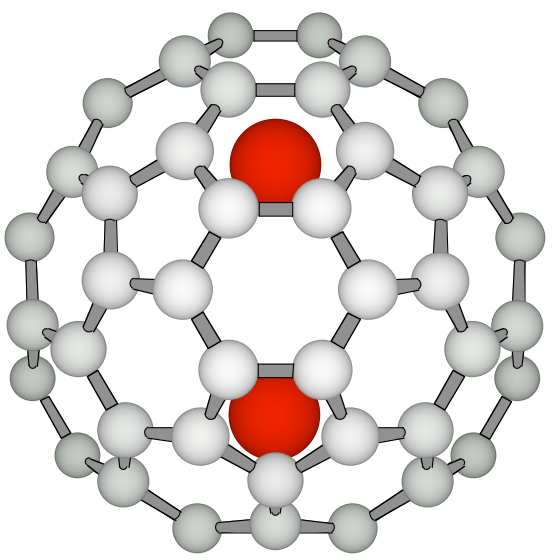

Two La-atoms are located on the y-axis. This structure is less stable by $17 \mathrm{kcal}$ $\mathrm{mol}^{-1}$ than the optimized structure.



Two La-atoms are located on or a bit off $\mathrm{C}_{3}$ axis; this is the most stable structure (optimized structure).

Table S1. Energy levels (eV) of orbits in Supporting Figure S5 for optimized structure of $\mathrm{La}_{2} @ \mathrm{C}_{78}$ : energy level (orbit No.).

\begin{tabular}{|l|l|l|l|l|}
\hline$-6.43(241)$ & $-6.43(242)$ & $-5.75(243)$ & $-5.74(244)$ & $-5.69(245)$ \\
\hline$-4.88(246)$ & $-3.45(247)$ & $-3.44(248)$ & $-3.36(249)$ & $-3.36(250)$ \\
\hline
\end{tabular}

